\title{
ESTIMATIVA DA FASE DO CICLO ESTRAL POR CITOLOGIA VAGINAL EM CADELAS (Canis familiaris, LINNAEUS, 1758) DA REGIÃO DE ITUVERAVA-SP
}

\author{
COSTA, Elaine Cristina Ferreira da ${ }^{1}$ \\ LÉGA, Elzylene ${ }^{2}$ \\ NEVES, Letícia ${ }^{1}$
}

Recebido em: 2009-10-01

Aprovado em: 2009-10-30

ISSUE DOI: $10.3738 / 1982.2278 .310$

RESUMO: O ciclo estral da cadela se divide em fases sucessivas e individualizadas, sendo elas: proestro, estro, metaestro e diestro, seguido de anestro. Estas fases podem ser diferenciadas por exames hormonais ou citológicos, o que permite estimar o período de fertilidade, distúrbios do ciclo estral e inatividade sexual. Desta forma, o presente trabalho teve o intuito de realizar exames citológicos vaginais em cadelas e identificar seus escores reprodutivos. Para tanto, foram realizados exames em 91 fêmeas escolhidas aleatoriamente, durante a campanha de vacinação anti-rábica na cidade de Ituverava-SP, sendo encontrados $14,2 \%$ destes animais em proestro; $23,0 \%$ em estro; $3,2 \%$ em diestro e $52,7 \%$ em anestro.

Palavras-chave: Ciclo estral. Citologia vaginal. Cadela.

SUMMARY: The estrous cycles of bitches are divided into successive and individual phases. The phases are: proestrus, estrus and metaestrus following anestrus. These phases can be differentiated by hormone or cytological examinations that permit estimating the fertility period, estrus cycle disturbances, and sexual inactivity. In this way, the present study has the objective to perform cytological vaginal examinations in bitches in order to identify the reproductive score of these animals during an anti-rabies vaccination campaign in the city of Ituverava, Sao Paulo. The results performed in 91 animals indicated an outcome of $14,2 \%$ in proestrus, $23,0 \%$ in estrus, $3,2 \%$ in diestrus, and $52,7 \%$ in anestrus.

Keywords: Estrus cycle. Vaginal cytology. Bitch.

\section{INTRODUÇÃO}

Os ciclos reprodutivos correspondem aos fenômenos rítmicos observados em todos os mamíferos, exceto em alguns primatas, nos quais há períodos regulares, mas limitados de receptividade sexual, que ocorrem em intervalos característicos para cada espécie. Um intervalo de ciclo é definido como o tempo desde o início do período de receptividade sexual até o período seguinte, ou como o intervalo entre sucessivas ovulações. Os processos periódicos que ocorrem nos órgãos reprodutores

\footnotetext{
${ }^{1}$ Acadêmica do Curso de Medicina Veterinária da Faculdade Dr. Francisco Maeda - FAFRAM Ituverava, SP.

${ }^{2}$ Docente do Curso de Medicina Veterinária da Faculdade Dr. Francisco Maeda - FAFRAM - Ituverava, SP- lenelega@hotmail.com
} 
influenciaram todo o organismo tanto no comportamento como no metabolismo. A duração e evolução do ciclo estral nos animais domésticos apresentam diferenças consideráveis (HAFEZ; HAFEZ, 2004).

De um ponto de vista prático, um animal macho ou fêmea atinge a puberdade quando estiver capaz de liberar gametas e de manifestar uma seqüência completa de comportamento sexual. A puberdade é basicamente o resultado de um ajuste gradual entre atividade crescente gonadotrófica e a habilidade das gônadas em assumir simultaneamente a esteroidogênese e a gametogênese (THADEI, 2008).

As cadelas atingem a puberdade quando estão em média com 7 a 8 meses de idade, porém as raças de porte pequeno têm a sua puberdade mais cedo, em torno de 6 7 meses, em comparação com cadelas de raças de grande porte que iniciam seu ciclo reprodutivo ao redor de 9 a 12 meses de idade. Os primeiros ciclos da cadela podem ser em intervalos menores ou maiores, até que se estabeleça a normalidade. Normalmente as cadelas possuem um intervalo de 6 meses entre cada ciclo, porém para raças grandes como Pastor Alemão pode-se considerar o intervalo de cinco meses e para cadelas da raça Basenji, o intervalo de 12 meses, podem ser considerados normais (CRUSCO, 2005).

O ciclo estral é dividido em diferentes fases, sucessivas e individualizadas, sendo elas, proestro, estro, metaestro, diestro, seguida de uma fase chamada anestro (BEAVER, 2001).

O início da fase de estro pode ser razoavelmente determinado recorrendo à citologia vaginal, a qual se baseia nas alterações quantitativas e qualitativas da chave celular. As células epiteliais vaginais sofrem alterações morfológicas sob a ação das concentrações crescentes de estrógeno. Este estimula a proliferação do epitélio vaginal, que passa de uma espessura de poucas camadas celulares no anestro para uma espessura de 20 a 30 até 100-150 camadas de células no fim do proestro. $\mathrm{O}$ afastamento das células epiteliais da membrana basal epitelial estimula um processo degenerativo de morte celular associado a queratinização citoplasmática (ALAN et al, 2007).

O período fértil da cadela estende-se do final do proestro ao meio do estro. Cada uma dessas duas fases do ciclo estral da cadela pode durar de três dias a três semanas, com duração média de sete a dez dias (CONCANNON, 1989).

Durante estudos citológicos para determinar o melhor momento para acasalamento nas cadelas, utiliza-se swab para estudos bacteriológicos. A flora bacteriana vaginal de uma cadela saudável varia de acordo com o ciclo estral. Amostras 
vaginais obtidas de 1756 cadelas tiveram crescimento bacteriano em 90,7\% dos casos (MULLER, 2006).

A composição vaginal e uterina bem como a quantidade de bactérias pode variar durante o ciclo estral. Encontraram bactérias dos gêneros: Lactbacillus sp, Alpha hemolytic streptococai, Staphylococus intermediarias, Pasteurella multocida e E.coli, presentes na vagina e útero de cadelas (JANOWSKI et al, 2008).

A ovulação corresponde à ação do hormônio luteinizante (LH) sobre o folículo que passa a sintetizar enzimas hidrolíticas capazes de desintegrar a matriz de tecido conjuntivo fragilizando a parede do folículo e permitindo o seu rompimento. Conforme, a manifestação o desenvolvimento dos ciclos estrais dos animais podem ser classificados em: poliéstricos estacionais como as éguas, ovelhas e cabras; poliéstricos não estacionais como as vacas e, monoéstricos, como as cadelas (CRUSCO; MORAES, 2005).

A avaliação da fase do ciclo estral é de fundamental importância para o controle do ciclo reprodutivo das cadelas. Desta forma, a citologia vaginal trata-se de método rápido, prático e eficaz na identificação da fase do ciclo estral o que permite fazer cruzamentos programados e prevenir gestação indesejável, bem como o aumento da população de cães errantes.

Ainda, a citologia vaginal pode auxiliar em programas de inseminação artificial na espécie canina como alternativa para animais impossibilitados de realizar monta natural por problemas anatômicos e comportamentais, bem como para prevenção de transmissão de agentes infecciosos e uso de sêmen refrigerado e congelado. Para o acompanhamento da cadela, a forma mais prática e usual é através do seu comportamento sexual associado à citologia vaginal. A inseminação artificial deve ser realizada quanto a fêmea está receptiva ao macho e apresenta uma citologia como pelo menos 70\% de células superficiais (LEÃO, 2003). No entanto, Jacomini; Moreira; Cunha (2006) referiram que a inseminação artificial pode ser realizada após o aparecimento de $100 \%$ de células superficiais com o máximo delas anucleadas, independente de ainda haver ou não corrimento vaginal sanguinolento.

O presente trabalho versa sobre o ciclo estral da espécie canina e teve por objetivo avaliar o escore reprodutivo de cadelas da região de Ituverava-SP através de citologia vaginal e verificar se existe algum tipo de sazonalidade para esta espécie. 


\section{MATERIAL E MÉTODOS}

O material foi colhido durante a campanha de vacinação realizada no município de Ituverava-SP, em setembro de 2008, sendo para tanto preparado um "stand" contendo mesa de atendimento (figura 1) onde os animais eram colocados para a colheita.

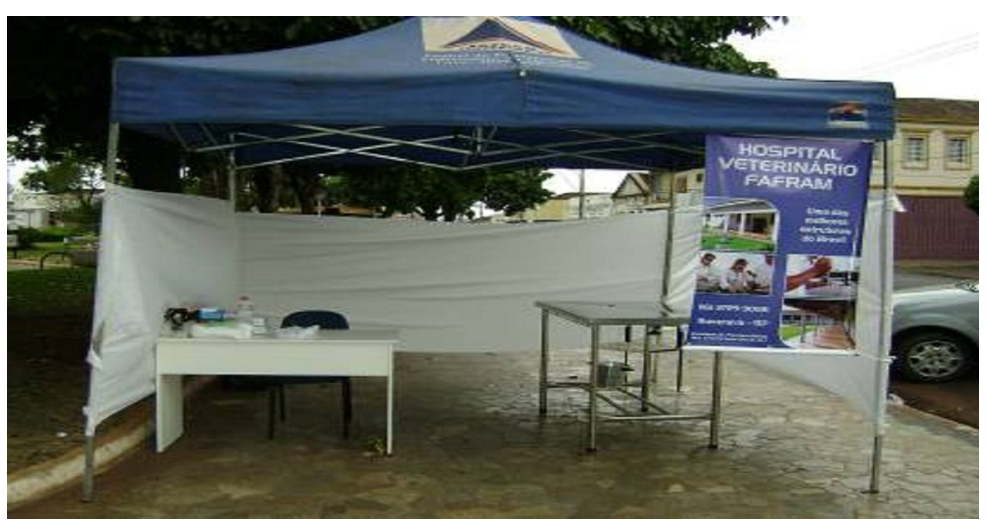

Figura 1: Imagem fotográfica do stand da Faculdade Dr. Francisco Maeda, com mesa de atendimento para vacinação anti-rábica e colheita de material citológico vaginal. Ituverava-SP. 2008.

Foram utilizadas 91 cadelas escolhidas de forma aleatória de um ou mais postos durante a campanha de vacinação anti-rábica realizada na cidade de Ituverava-SP, sob supervisão de vigilância sanitária do município, sendo feita paralelamente, rápida análise na forma de questionário para obtenção de dados quanto à idade, número de partos, acasalamentos e uso de anticoncepcionais.

Cada fêmea foi submetida à limpeza da região vaginal com solução fisiológica (Figura 2) seguida da realização da citologia com auxílio de swab introduzido em ângulos, inicialmente, de $45^{\circ}$ e depois $180^{\circ}$ (Figura 3) para que se obtivesse material da região mais cranial da vagina, sendo este material fixado em lâminas devidamente identificadas e numeradas (Figura 4).

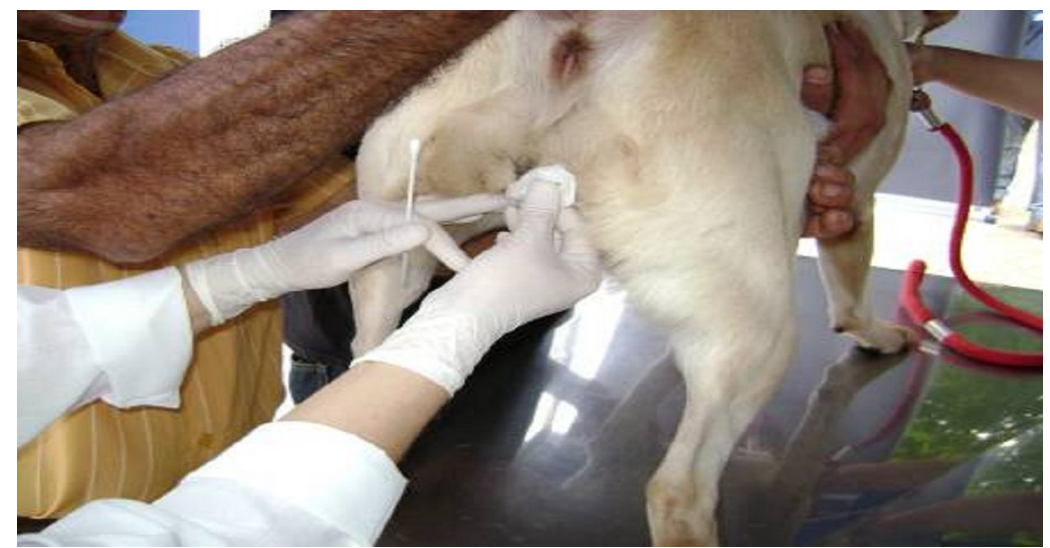

Figura 2: Imagem fotográfica da realização da anti-sepsia para a colheita de material para citologia vaginal na espécie canina. Ituverava-SP. 2008. 
As lâminas foram coradas no Laboratório de Reprodução Animal do Hospital Veterinário da Faculdade Dr. Francisco Maeda - Ituverava - SP, com corante do tipo Panótico Rápido ${ }^{3}$ (Figura 4).

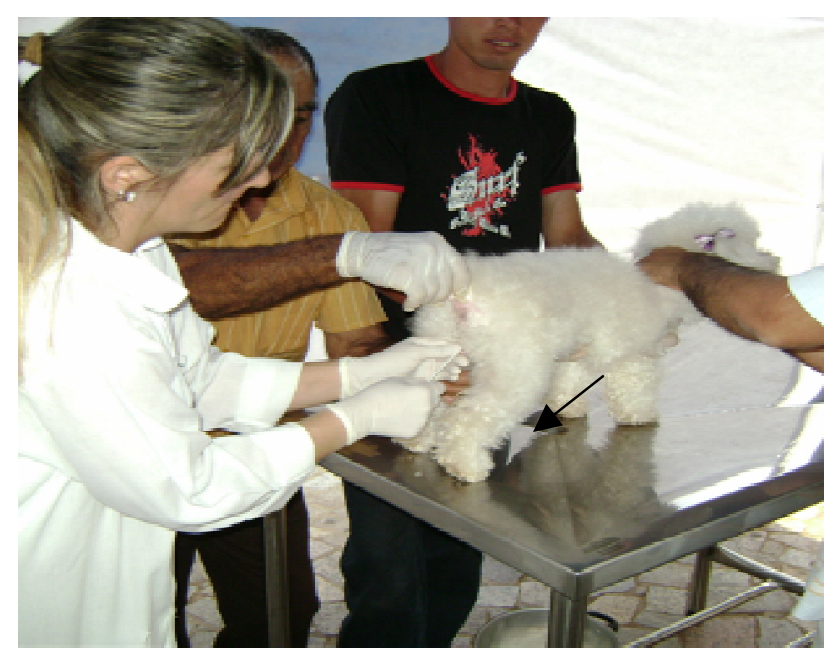

Figura 3: Imagem fotográfica do procedimento de colheita de material citológico, realizado através de swab (seta) em uma cadela. Ituverava-SP. 2008.

Após a coloração e secagem, cada lâmina foi submetida à microscopia óptica com aumento de 40x, sendo avaliada a porcentagem de células, parabasais, intermediárias e superficiais (figura 5). A partir deste valor, cada fêmea foi classificada. Os dados obtidos na anamnese, foram então associados a porcentagem de células encontradas na citologia vaginal de cada cadela e, a partir daí, as fêmeas foram classificadas conforme a fase do ciclo estral: em proestro, estro, metaestro, diestro e anestro.
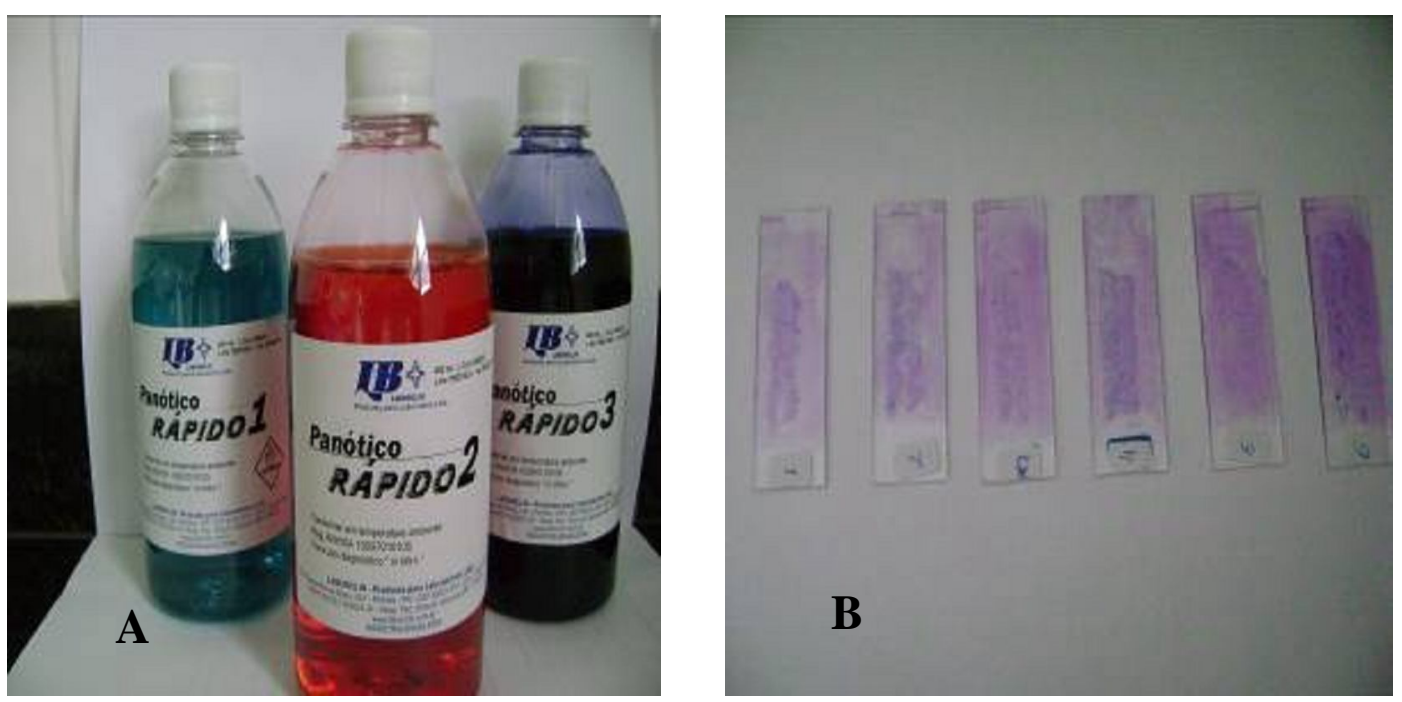

Figura 4: Imagem fotográfica dos corantes tipo Panótico® (A) utilizado para coloração de lâminas (B) preparadas para interpretação de citologia vaginal de cadelas. ItuveravaSP. 2008.

\footnotetext{
${ }^{3}$ Labordin
} 

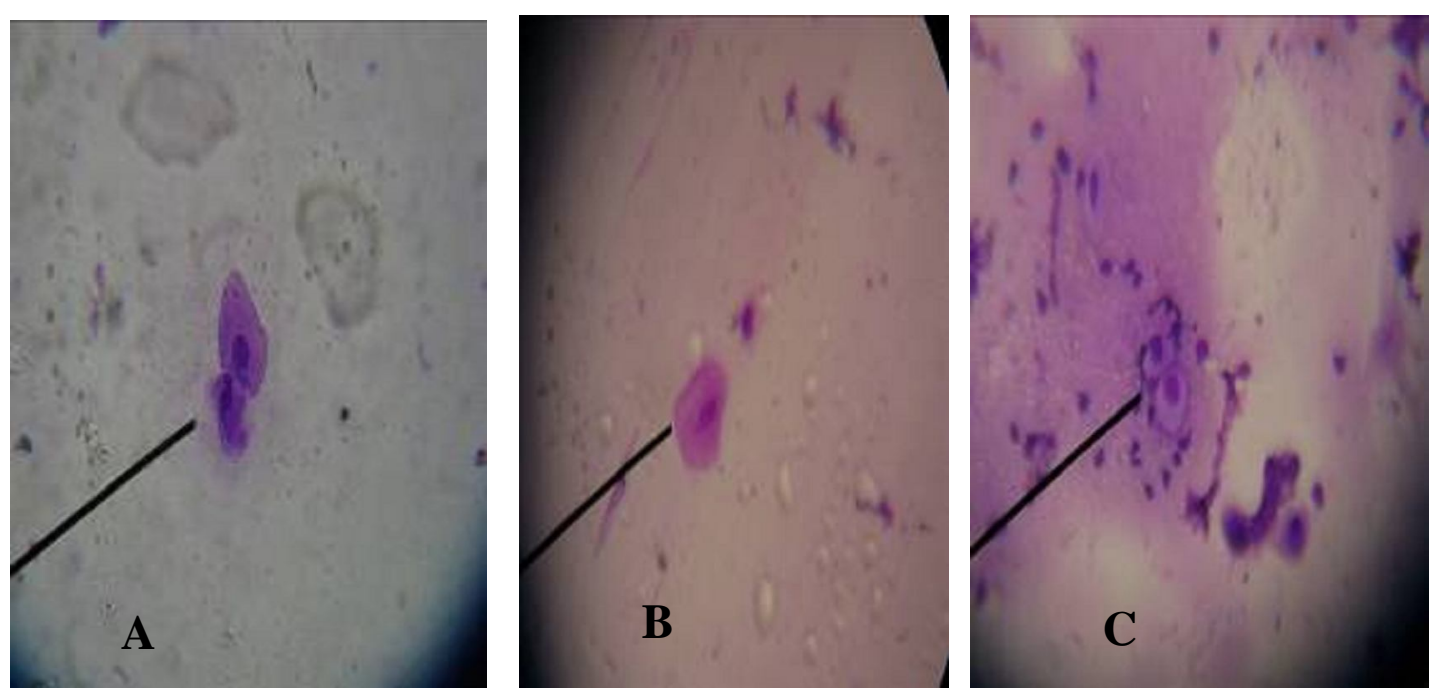

Figura 5: Aspectos citológicos de cadelas em proestro, ilustrando células intermediarias (A); em estro, mostrando célula superficial (B) e em diestro, mostrando célula parabasal (C). Faculdade Dr. Francisco Maeda. FAFRAM - Ituverava-SP. 2009.

Após determinação da fase do ciclo estral para cada animal, foi calculada a porcentagem de animais encontrada em cada fase do ciclo.

\section{RESULTADOS E DISCUSSÃO}

O ambiente preparado para colheita do material citológico vaginal foi suficiente para manter bem-estar aos animais examinados, visto que nenhum imprevisto foi observado e as cadelas puderam ser contidas e permanecer todo tempo com seus proprietários ou responsáveis. Desta forma, não houve dificuldade de ser obter o material, o qual foi colhido da vagina o mais cranial possível, para que secreções e células vestibulares não interferissem nos resultados (QUINTANILHA, 1992).

Todos os proprietários foram consultados previamente para que autorizassem o procedimento. Valendo ainda salientar que todos os métodos foram supervisionados por técnicos da Vigilância Sanitária.

Tabela 1: Número de cadelas distribuídas por fase do ciclo estral, submetidas à citologia vaginal durante campanha de vacinação anti-rábica realizada em Ituverava-SP 2008.

\begin{tabular}{cccc}
\hline Fase Reprodutiva & Predominância celular & $\begin{array}{c}\mathbf{N}^{\mathbf{0}} \text { de } \\
\text { animais }\end{array}$ & \% de animais \\
\hline Proestro & Intermediária & 13 & $14,2 \%$ \\
Estro & Superficial & 21 & $23,0 \%$ \\
Metaestro & Intermediária & 6 & $6,5 \%$ \\
Diestro & Parabasal & 3 & $3,2 \%$ \\
Anestro & Parabasal & 48 & $52,7 \%$ \\
\hline
\end{tabular}


Foram avaliadas um total de 91 cadelas de várias raças, com idades variando de 7 a 180 meses.

Destas fêmeas, 51 animais apresentaram predominância de células parabasais; 19, apresentaram predominância de células intermediárias e, em 21 cadelas, houve predominância de células superficiais (Tabela 1).

Considerando que a fase de transição entre estro e diestro, conta com um acréscimo na dosagem do progesterona, optar-se pela classificação das fases do ciclo estral incluindo o metaestro (MIES FILHO, 1987; ALMEIDA, 1999).

Assim, os resultados obtidos incluíram 52,7\% de fêmeas em anestro; $23 \%$ de fêmeas em estro; $14,2 \%$ de fêmeas em proestro; $6,5 \%$ de fêmeas em metaestro e 3,2\% de fêmeas em diestro (Tabela 1).

Segundo Crusco; Moraes (2005), fêmeas com predominância de células parabasais podem encontrar-se em fase proestro, diestro ou anestro. A predominância de células intermediárias pode indicar fase de proestro ou metaestro e células superficiais confirmam a fase estral em período próximo à ovulação. Assim, como a predominância de mais de um tipo celular pode indicar mais de uma fase do ciclo estral, torna-se importante à obtenção do histórico reprodutivo como foi feito neste trabalho.

Durante a anamnese, alguns proprietários relataram data provável do último cio; administração de anticoncepcional e número de partos já ocorridos, no entanto, outros proprietários desconheciam algum ou todos os dados anteriores.

Portanto, neste estudo, a maioria das cadelas encontravam-se um anestro, não sendo estabelecido relação de sazonalidade na manifestação dos ciclos estrais para esta espécie. Para tanto, novos estudos em outras épocas do ano podem ser realizados.

Nos seis casos em que o uso de anticoncepcional foi relatado, o perfil citológico foi condizente com a predominância de células parabasais que indicam período progesterônico ou anestro, concordando com os relatos encontrados (CRUSCO; MORAES, 2005).

Desta forma, o escore reprodutivo na cadela pode ser estimada por citologia vaginal, o que ainda serve de auxílio tanto para diagnóstico diferencial de afecções, como para os programas de inseminação artificial (LEÃO, 2003; JACOMINI; MOREIRA; CUNHA, 2006). 


\section{CONCLUSÃO}

A citologia vaginal é um método auxiliar para estimativa do escore reprodutivo na espécie canina, no entanto, o histórico obtido através da anamnese torna os resultados mais fidedignos.

Além disso, o método é extremamente praticável visto que é realizado de maneira simples, rápido e com baixo custo.

\section{REFERÊNCIAS}

ALAN, M. et al. True vaginal prolapse in a bitch. Animal reproduction science. v.100, n. 3/4, p. 411- 414, 2007.

ALMEIDA, J. M. Embriologia veterinária comparada. Rio de Janeiro: Guanabara Koogan, 1999. 13 p.

BEAVER, B. V. Comportamento canino: um guia para veterinários. São Paulo: Roca, 2001. 431p.

CONCANNON P.W. L. Hormonal and clinical correlates of ovarion cycles, ovulation, pseudopsegnaney, and pregnaney in dogs. Curr Vet Ther small anim pract. v.10, p. 1269-1282, $1989 . \quad$ Disponível em: http://www.iris.org/advances/concannon/concannon/chapter. Acesso em: 07 maio 2009.

CRUSCO, S. E. Fisiologia do ciclo estral em cadelas. 2005. Disponível na internet: http://www.bichoonline.com.br/artigos/Xsc0001.html. Acesso em: 07 abr. 2009.

HAFEZ, E. S. S.; HAFEZ, B. Reprodução animal. 7. ed. Barueri: Manole, 2004. 513p.

JACOMINI, J. O.; MOREIRA, C. F.; CUNHA, G. N. Uso da inseminação artificial como rotina em programas de reprodução de cadelas da raça Bulldog. Vet. Not., Uberlândia, v. 12, n. 2, p.139, set. 2006. Disponível em: <http://www.vetnot.famev.ufu.br/index.php>. Acesso em: 20 maio 2009.

JANOWSKI, T. et al. Vaginal and uterine bacterial flora at different stages of the estrus cycle in bitches. Medycyna Weterynaryjna. v. 64, n. 4, p. 444-446, 2008.

LEÃO, K. M. Técnicas de inseminação artificial. 2003. 33 f. Reprodução Animal (Pos-graduação) - Curso de Medicina Veterinária, Unesp, Botucatu, 2003. Disponível em: <www.geocities.com/andbt/semi03/Karen.pdf>. Acesso em: 19 maio 2009.

MIES FILHO, A. Reprodução dos animais. 6 ed. Porto Alegre: Sulinac, 1987, v.1 $315 \mathrm{p}$. 
MORAES, I. A. Reprodução nas fêmeas. 23. fev.2009. Disponível em:

http://www.uff.br/fisiovet/Conteudos/reproducao_femeas.htm. Acesso em 20 maio.

2009.

MULLER, E. Bacteriological investigation of vaginal swabs in the dog and cat. Kleintierpraxis. v. 51, n. 5, p. 278-279, 2006.

PAULA, V. M. C. de. Manual para elaboração e apresentação de monografia. Ituverava: FEI, 2005. 58p.

POST, K. Canine vaginal cytology during the estrous cycle. Practitioner Review. p. 101-104. 1985.

QUINTANILHA, A. M. N. P. Distúrbios da vagina e útero. In: NELSON, R.W., COUTO, C.G. Fundamentos de medicina interna de pequenos animais. Rio de Janeiro: Guanabara Koogan, 1992.

THADEI, C.L. Pseudociese nas cadelas. 26 .maio.2008. Disponível em:

http://www.saudeanimal.com.br/artig161_print.htm. Acesso em: 07 mar. 2009. 
